Dicle Tıp Dergisi / Dicle Med J (2018) 45 (3) : 317-325

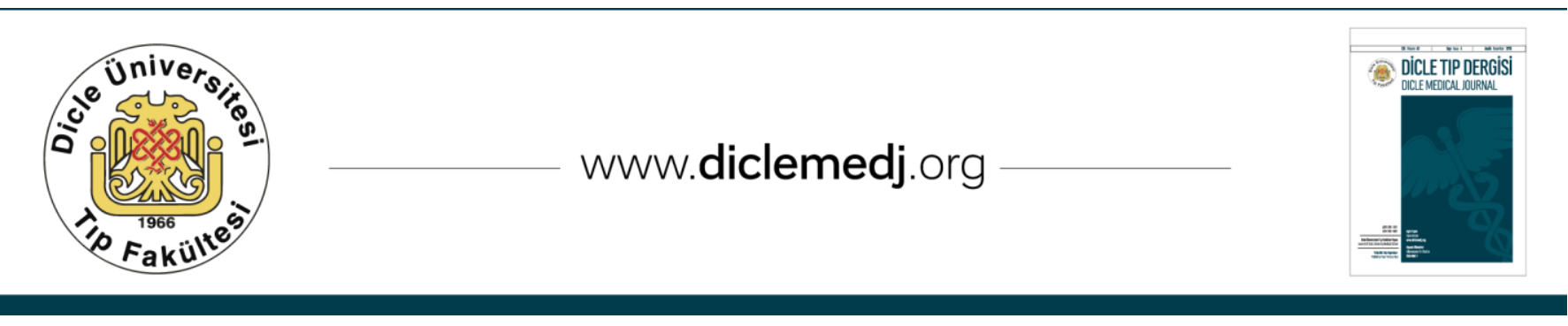

Özgün Araștırma / Original Article

\title{
İntrakranial Menenjioma Olgularının Değerlendirilmesi: 72 Hastanın Analizi
}

\author{
Yahya Turan', Tevfik Yılmaz ${ }^{2}$ \\ 1 Dicle Üniversitesi Tıp Fakültesi Beyin Cerrahisi ABD. Diyarbakır, Türkiye ORCID: 0000-0002-8048-6033 \\ 2 Dicle Üniversitesi Tıp Fakültesi Beyin Cerrahisi ABD. Diyarbakır, Türkiye ORCID: 0000-0002-1444-3246
}

Geliş: 30.03.2018, Revizyon: 25.04.2018, Kabul Tarihi: 27.04.2018

Öz

Amaç: Kliniğimizde 2012-2018 yıllarında ameliyat olmuş ve menenjiom tanısı almış olan 72 hasta retrospektif olarak klinik, radyolojik ve patolojik bulgularıyla incelenerek literatür eşliğinde tartışıldı.

Yöntemler: Hastaların yaşları, cinsiyetleri, klinik bulguları, radyolojik görüntüleri, yerleşim yerleri, ameliyat kayıtları ve patolojik olarak aldıkları tanıları incelendi.

Bulgular: 72 intrakranial menenjiomalı hastanın 47 (\%65,3)'i kadın, 25 (\%34,7)'i erkektir. Kadın/Erkek oranı: 1.88'dir. Olgular 19-78 yaş aralığında olup, yaş ortalaması 44.7'dir. Sıklık sırasına göre başvurma nedenleri ve nörolojik muayene bulguları: Baş ağrısı $(\% 72,2)$, bulantı-kusma $(\% 37,5)$, epilepsi $(\% 25,0)$, motor defisit $(\% 20,8)$ 'dir. En sık yerleştikleri lokalizasyonlar: konvexite 17 (\%23,7), parasagital $14(\% 19,5)$, sfenoid kanat 9 (\%12,59 bölgesidir. Cerrahi tedavideki rezeksiyonumuzun Simpson klasifikasyonuna göre; hastaların $57(\% 79,2)$ 'i grade I, 8 (\%11,1)'i grade II, $2(\% 2,8)$ 'i grade III, $4(\% 5,5)$ 'i grade IV ve $1(\% 1,4)$ 'i grade V olarak değerlendirilmiștir. Histopatojik tanıları ise sıklık sırasına göre; $29(\% 40,3)$ meningotelyomatöz, 13 (\%18,1) fibröz, $9(\% 12,5)$ transisyonel, $6(\% 8,3)$ oranında psammomatöz tip şeklinde tespit edildi.

Sonuç: İntrakranial menenjiomalar malign tipleri dışında; genellikle benign karekterde yavaş büyüyen, erken tanı konup, total çıkarıldığında tam kür sağlanan, rekürrens oranı çok düşük olan tümörlerdir. Menenjiomalarda cerrahi kararın verilmesinde ve sürvide; hastaların yaşı, preoperatif performans skalası, tümörün lokalizasyonu, büyüklügü, rezeksiyon derecesi, histopatolojik özellikleri gibi birçok faktör rol oynamaktadır. Asemptomatik, küçük boyutta, ameliyata uygun olmayan, yaşlı, kafa tabanı, kavernöz sinüs gibi ulaşılması zor lokalizasyonlarda bulunan hastalarda seri görüntülemelerle yakın takip ve radyocerrahi tercih edilebilir. MRG takibi 3. ay, 6. ay ve sonrasında yıllık takipler şeklinde ve takipte gerek görülürse, büyüme olursa cerrahi/radyocerrahi önerilir. Genç olan ve kalsifikasyonu bulunmayanlarda hızlı büyüme riski nedeniyle cerrahi düşünülmelidir.

Anahtar kelimeler: Intrakranial menenjiomlar, kranial cerrahi, klinik çalışma, radyocerrahi

DOI: $10.5798 /$ dicletip.419310

Yazışma Adresi / Correspondence: Yahya Turan, Dicle Üniversitesi Tıp Fakültesi Beyin Cerrahisi ABD. Diyarbakır, Türkiye e-mail: dryahyaturan@hotmail.com 


\title{
Assessment of Cases with Intracranial Meningioma: Analysis of 72 Patients
}

\begin{abstract}
Objective: 72 patients, operated and diagnosed as meningioma in our clinic, are discussed retrospectively with the clinical, radiological and histopathological findings in the enlightenment of literature.

Methods: Patients' ages, sex, clinical findings, radiological images, tumors' locations, operative records and histopathological diagnosis were reviewed.

Results: Of 72 patients with intracranial meningioma, 47 (65.3\%) were female and 25 (34.7\%) were male. The female / male ratio is 1.88. The cases are between 19 and 78 years old and the average age is 44.7. Causes and neurological examination findings were as follows: Headache (72.2\%), nausea and vomiting (37.5\%), epilepsy (25.0\%) and motor deficit (20.8\%). The most common localizations were: convexity 17 (23.7\%), parasagittal 14 (19.5\%), sphenoid wing $9(12.59 \%)$. According to Simpson classification of resection in surgical treatment; 57 (79,2\%) patients were grade I, 8 (11.1\%) were grade II, 2 (2.8\%) were grade III, 4 (5.5\%) were grade IV and 1 (\%1.4) grade V .Histopathologic diagnoses are according to frequency; 29 (40.3\%) meningothelial, 13 (18.1\%) fibrous, 9 (12.5\%) transitional and 6 (8.3\%) psammomateous type were detected.

Conclusion: Apart from malignant types of intracranial meningioma; usually benign tumors that grow slowly, when they are diagnosed early and removed totally are fully cured, and have very low recurrence rates. About deciding on surgery and estimating the survival rates the patient's age, preoperative performance scale, the tumor location, size, degree of resection, histopathological features and as many factors play roles. Close follow-up with serial imaging and radio surgery may be preferred for tumors which area symptomatic, small in size, or difficult to reach due to localizations like skull base or cavernous sinus, in elderly patients who are inappropriate for surgery. MRI follow-up is recommended at 3rd month, at 6th month, and afterwards annual follow-ups are recommended. Surgery should be considered in young patients and in those tumors without calcification because of the risk of rapid growth.
\end{abstract}

Keywords: Intracranial meningiomas, cranial surgery, clinical study, Radiosurgery

\section{GíRiş}

Menenjiomalar orta-ileri yaş ve kadın nüfusta daha fazla görülen, çoğu benign olan ektraaksiyal lezyonlardır ${ }^{1-4}$. Menenjiomaların çoğu bening iken, atipik \%15 ve malign menenjiom ise \%2'dir-7. Ya klinik bir semptomla ve yahut insidental olarak teşhisı konulabilirr,4,8,9. Tümörün total olarak çıkarılması genellikle kür sağlar. Asemptomatik küçük tümörü olanlarda, yüksek ameliyat riski olan yaşlı hastalarda, kafa tabanı gibi cerrahi olarak zor ve derinde yerleșmiş olanlarda radyocerrahi yapılabilir10-12. Günümüzde kemoterapi ve hormon tedavisi; malign veya nüks etmiş hastalarda alternatif bir tedavi yöntemi olarak uygulanmaktadır ${ }^{3,13-15}$.

\section{YÖNTEMLER}

Kliniğimizde Ocak 2012- Ocak 2018 yıllarında opere edilmiş ve menenjiom tanısı almış olan toplam 72 hasta retrospektif olarak incelendi. Hastalara ait bilgiler, dosyaları incelenerek; anamnez, muayene bulguları, radyolojik görüntüleri, ameliyat raporları ve histopatolojik sonuçlarının değerlendirilmesi ile elde edildi. Hastaların yaşı, cinsiyeti, klinik şikâyetleri, nörolojik muayeneleri, lokalizasyonları ve patolojik tipleri tayin edildi. Radyolojik bulguları yerleşim yeri, vaskularitesi, hiperostozisin ve kalsifkasyonun olup olmamasına göre incelendi. Tümörlerin sınıflanmasında WHO klasifikasyonu kullanıldı.

\section{TARTIŞMA}

Menejiomalar, ilk defa 1614 yıllarında Felix Plater tarafından otopsi çalışmasında tarif edilmiştir. Fransız cerrah Antoine Louis ilk cerrahi raporu 1754 yılında yazmıştır $1,6,16$. Psammomatöz menenjioma 1847 yllında Virchow tarafından tariflenmiştir. Parasagital menenjiomanın ameliyatı ilk olarak 1910 yılında Cushing tarafından yapılmıştır 1,4,6,17. Menenjiomlar, glial tümörler dişında en sık görülen beyin tümörleridir. Tüm primer beyin 
tümörleri içinde yaklaşık \%20 bir orana sahiptir $^{4,8,18}$. Bu oran otopsi çalışmalarında \%30'ı bulmaktadır. Ayrıca bu otopsi çalışmalarının yaklaşık \%2'de insidental menenjioma tespit edilmiştir ${ }^{9,16,17,19 .}$ Menenjiomaların \%90'ı intrakranial ve bununda \%90’ı supratentoryal olarak yerleşir. Menenjiomalar spinal bölgede de görülebilmektedir ${ }^{20}$. Görülme sıklığı yaşla artar. En sık 40 - 60 yaş arası yetişkinlerde görülmektedir ${ }^{1,8,9}$. Kadınlarda yaklaşık 2 kat daha sıktır. Bizim serimizde, hastaların 47 $(\% 65,3)$ 'i kadın, $25 \quad(\% 34,7)$ 'i erkekti. Kadın/Erkek oranı: 1.88'dir. Olguların en küçügü 19, en büyüğü 78 yaşındadır. 42 hasta 30-59 yaş grubundadır (Bu hastalar tüm hastaların \%58,.3'ünü oluşturmaktadır). Hastaların yaş ortalaması 44.7 olarak saptanmıştır.

Menapoz sonrasındaki kadınlarda fazla görülmesinin sebebi olarak; artmış olan endojen hormon seviyeleri ve tedavide kullanılan eksojen hormon seviyeleri gösterilmiştir10,11,21. Menenjiomalarla ilişkili olarak radyoizotop yöntemiyle progesteron ve östrojene ait reseptörler araştırılmış ve günümüzde steroid hormonuna ait reseptörlerine karşı geliştirilmiş olan monoklonal antikorlar hastalarda tespit edilmiştir ${ }^{12-}$ 14. Etyolojik faktörler arasinda viral enfeksiyonlar, geçirilmiş travmalar, bazı malignitelerin predispozisyonu ve radyaterapi öyküsü bulunmaktadır. Kesin olarak gösterilmemişse de olgularda $1 / 3$ oranında geçirilmiş ciddi travma öyküsü bulunmaktadır ${ }^{1-}$ $3,8,9$. Risk faktörlerinden en bilineni radyasyona maruz kalmadır. Radyoterapi alanlarda 4 kat fazla menenjioma görüldüğü rapor edilmiștir ${ }^{1,8,11}$.

\section{Klinik}

Tüm beyin tümörlerinde olduğu gibi klinik bulgular lezyonun yerleşim yerine göre değişmektedir. Menenjiomalar genellikle yavaş büyüyüp klinik tablo ortaya çıkana kadar tespit edilmezler. Semptom vermeyen ve insidental olarak tanı konulanların çoğu radyolojik görüntülemelerde $2 / 3$ oranında stabildir ${ }^{1,2,8,16}$. Büyüme hızı yılda 2-4 mm ve tümörün ikileme süresi yaklaşık 20 yıl kadardır 4,6,9,17. Yavaş ilerleyen baş ağrısı sık görülmektedir. Meninjiomaların klinik semptomları sıklık sırasına göre \%84,8 oranında baş ağrısı, $\% 42,15$ bulantı ve kusma, \%27,61 epileptik atak, \%18,60 motor defisit, \%16,86 görme bozuklukları ile ve $\% 10$ oranında ise asemptomatik şeklinde prezante olmaktadır ${ }^{1,4,8,22}$. Bizim serimizde ise, sıklık sırasına göre başvurma nedenleri ve nörolojik muayene bulguları: Baş ağrısı $(\% 72,2)$, bulantıkusma $(\% 37,5)$, epilepsi $(\% 25,0)$, motor defisit $(\% 20,8)$ 'dir (Tablo 1). Nörolojik muayenesi normal olan $9(\% 12,5)$ hasta bulunmaktayd. Hastaların çoğu, yakınmalar başladıktan 6 ay-3 yıl içinde tıbbi yardım için kliniğimize başvurmuştur.

Tablo 1. Olguların Semptom ve Muayene Bulguları

\begin{tabular}{|lc|}
\hline Baş ağrısı & $52(\% 72,2)$ \\
Bulantı- Kusma & $27(\% 37,5)$ \\
Epilepsi & $18(\% 25,0)$ \\
Motor defisit & $15(\% 20,8)$ \\
Bilinç değişikliği & $13(\% 18,1)$ \\
Duyu defisiti & $11(\% 15,3)$ \\
Kişilik değişikliği & $10(\% 13,9)$ \\
Görme bozukluğu & $9(\% 12,5)$ \\
Papil ödemi & $9(\% 12,5)$ \\
Konuşma bozukluğu & $8(\% 11,1)$ \\
Ataksi & $5(\% 6,9)$ \\
Kranial sinir tutuluşu & $2(\% 2,7)$ \\
İșitme bozukluğu & $2(\% 2,7)$ \\
\hline
\end{tabular}

\section{Radyolojik bulgular}

Kontrastlı BT ve MRG görüntülemeleri teşhis ve tedavilerin planlamasında çok büyük öneme sahiptirler $1,2,21$. X- ray grafilerde karakteristik bazı bulgular gözlenebilir. Tümöral kalsifikasyonlar, güneş ışı̆̆ı görüntüsü veren 
kranium hiperosteozisi, sekonder olarak gelişen osteolititik bulgular, genişlemiş orta serebral arter oluğu, posterior klinoidin erozyon göstermesi ve sütürlerdeki separasyon gibi bulgular X-ray'de saptanabilir. En sik gözlenen röntgen belirtisi hiperostozdur 1,2,4,8,18.

Yavaş büyüyen menenjiomanın kraniumda meydana getirdiği kronik belirtileri en iyi gösteren radyolojik tetkik BT'dir. Kalsifikasyon yaklaşık \%25 gibi bir oranda görülür ve hiperosteozis gibi BT'de net bir şekilde görüntülenebilir6,9,16,17. Kontrastsız BT kesitlerinde menenjiomalar düzgün sınırlı, \%25 izo veya $\% 75$ hiperdens olarak görünürler. Bazen tümör merkezinde veya periferde yerleşmiş küçük kistler gözlenebilir. BT'de genellikle geniş bir dural taban gözlenir. Kontrastlı BT kesitlerinde sıklıkla yoğun ve homojen kontrast tutulumu yanında dural tail gözlenir ${ }^{2,4-6,21}$.

MRG teşhis ve cerrahi plan için en değerli tanı yöntemidir. Atipik menenjioma, görüntüsü ile bazen \%10-15 oranında malign gliom ve metastaz ile karıştırılabilir. T1-ağırlıklı nonkontrast sekanslarda \%60-90 izointens olarak izlenirken, \%10-30 hipointens olarak görüntülenirler. T2-ağırlıklı sekanslarsa ise \%30-40 hiperintens, \%50 olgu ise izointens olarak görüntülenir. Ayrıca T2-ağırlıklı imajlarda \%80-90 kadar bir oranda heterojen görünüme sahiptir. $\mathrm{Bu}$ heterojenite tümör vaskülaritesi, kistik yapısı ve tümörün kalsifiye olmasından kaynaklanmaktadır ${ }^{4,23,24}$. MRG'de yoğun ve homojen kontrast tutulumu gözlenir. Menenjiommalarda karakteristik bir özellik olan, ancak spesifisitesi olmayan dural tail (kuyruk) bulgusuda gözlenir (Resim 1). Bu bulgu iyi kontrast tutan ve lezyon sinırından daha ileri uzanmış kalınlaşmış dura görüntüsü şeklinde tariflenir 2,4,24,25. Ayrıca MRG venografi, dural sinüslerin ve büyük kortikal venlerin durumu hakkında bilgi vermektedir. Özellikle sekretuvar menenjiomma hastalarında peritümöral ödem gözlenir (Resim 2). Buradaki ödemin tümör lokalizasyonu, histopatolojik tipi, vaskülaritesi, tümörün sekretuar olması, venöz yapıların basıya uğraması gibi birçok faktörün etkili olduğu bilinmektedir 21,23,25.

Serebral DSA ve 3D BT anjio sıklıkla cerrahi planlamadan önce vasküler yapıların tümörle ilişkisini değerlendirebilmek için kullanılmaktadır. Embolizasyon, preop hemostazın sağlanabilmesi için önemli bir yöntemdir. Genişlemiş olan multipl dural arterlerde "sunburst effect" görüntüsü, tümör içi venöz yapılardaki staz sonucu vasküler lekelenmeler görülebilmektedir 1,2,18,21.

MRG spektroskopisinde \%20 gibi bir oranda kreatin piki görülebilmektedir. Atipik menenjiomaların \%60'ında laktik asit piki olabileceği öne sürülmektedir ${ }^{1,23,24}$.

Biz serimizde tanı yöntemi olarak Beyin BT 72 $(\% 100)$, MRG $71(\% 98,6)$ ve lüzum görülmesi halinde serebral DSA $3(\% 4,2), 3 \mathrm{D}$ BT Angiografi $15(\% 20,8)$ ve MRG -Venografi 7 $(\% 9,7)$ olguda kullanıldı. Sirayla en sık yerleştikleri lokalizasyonlar: konveksite 17 $(\% 23,7)$, parasagital $14(\% 19,5)$, sfenoid kanat $9(\% 12,5)$, tüberkülum sella $7(\% 9,7)$ ve falks 7 $(\% 9,7)$ bölgesidir (Tablo 2) (Resim 3-6).

Patolojik özellikler

Tablo 2. Menenjiomaların radyoljik olarak yerleşim yerlerine göre dağılımı

\begin{tabular}{|ll|}
\hline Konveksite & $17(\% 23,7)$ \\
Parasagittal & $14(\% 19,5)$ \\
Sfenoid kanat & $9(\% 12,5)$ \\
Tuberkulum sella & $7(\% 9,7)$ \\
Falks & $7(\% 9,7)$ \\
Olfaktor oluk & $6(\% 8,4)$ \\
Tentoryal & $3(\% 4,2)$ \\
Pontoserebellar köşe & $2(\% 2,7)$ \\
Foramen magnum & $2(\% 2,7)$ \\
Klival & $2(\% 2,7)$ \\
İntraventriküler & $1(\% 1,4)$ \\
Orta fossa & $1(\% 1,4)$ \\
Multipl & $1(\% 1,4)$ \\
\hline
\end{tabular}


WHO klasikasyonuna göre menenjiomalar üç ana gruba ayrılmıștır ${ }^{26}$ (Tablo 3). Histopatolojik tanı aşamasında epitelyal membran antijeni, laminin, vimentin, fibronektin, CEA, S100 ve keratin gibi ajanlar kullanılmaktadır ${ }^{5,18,19,21}$. Literatüre bakıldığında en sık görülen histopatolojik tipin meningotelyomatöz tip olduğu görülmektedir. İkinci olarak transizyonel tipin olduğu bildirilmektedir ${ }^{1,21,24}$. Bizim serimizde 29 $(\% 40,3)$ ile en sik meningotelyomatöz, 13 $(\% 18,1)$ fibröz, $9(\% 12,5)$ transisyonel, $6(\%$ 8,3 ) oranında psammomatöz tip şeklinde tespit edildi. Histopatolojik tiplerin görülme sıklı̆̆ Tablo 4 ile gösterilmektedir.

Tablo 3. Menenjiomaların WHO Sinıflaması

\begin{tabular}{|cl|}
\hline I Menenjioma & Grade \\
- meningotelyal & (gradeI) \\
- fibröz & (gradeI) \\
- transizyonel & (gradeI) \\
- psammomatöz & (gradeI) \\
- angiomatöz & (gradeI) \\
- mikrokistik & (gradeI) \\
- sekretuar & (gradeI) \\
- lenfoplasmositten zengin & (gradeI) \\
- metaplastik & (gradeI) \\
II Atipik & (grade II) \\
kordoid & (grade II) \\
clear cell & (grade II) \\
III Anaplastik & (grade III) \\
Papiller & (grade III) \\
Rabdoid & (grade III) \\
\hline
\end{tabular}

Tablo 4. Histopatolojik tanılar

\begin{tabular}{|ll|}
\hline Histolojik Tanı & Görülme sıklı̆̆ \\
Meningotelyal & $29(\% 40,3)$ \\
Fibröz & $\mathbf{1 3}(\% 18,1)$ \\
Transizyonel & $\mathbf{9}(\% 12,5)$ \\
Psammomatöz & $\mathbf{6}(\% 8,3)$ \\
Angiomatöz & $\mathbf{3}(\% 4,2)$ \\
Papiller & $\mathbf{2}(\% 2,7)$ \\
Sekretuar & $\mathbf{1}(\% 1,4)$ \\
Atipik & $6(\% 8,3)$ \\
Malign & $\mathbf{3}(\% 4,2)$ \\
\hline
\end{tabular}

\section{Tedavi}

Menenjiommalarda primer tadavi cerrahidir. Hastanın yaşı, kliniği, preoperatif performans skoru gibi hastaya bağlı faktörler ile; semptom, rezeksiyon, tedavinin amacı gibi tedaviye bağlı faktörler değerlendirilerek cerrahi kararı ona göre verilmelidir. Total rezeksizyon ile tam olarak kür sağlanır 12,22,27,28. Bu eksizyon derecesi postoperatif ilk 72 saatte kontrastlı BT veya MRG ile kontrol edilebilmektedir. Tümörün nüks etmesi, eksizyon derecesine ve histopatoloji sonucuna bağlı olarak değişmektedir ${ }^{3,14,27,29}$. Cerrahi rezeksiyon için en sik kullanılan dereceleme sistemi Simpson sinıflamasıdır. Simpson siniflamasında grade yükseldikçe rekürrens oranıda artmaktadır. Grade 1 için 10 yıllık rekürrens oranı \%9 iken, grade 3 için bu oran \%29'a yükselmektedir (Tablo 5) ${ }^{1,3,12,30,31}$. Bizim serimizde cerrahi tedavideki rezeksiyonumuzun Simpson klasifikasyonuna göre; hastaların $57(\% 79,2)$ 'i grade I, $8(\% 11,1)$ 'i grade II, $2(\% 2,8)$ 'i grade III, $4(\% 5,5)$ 'i grade IV ve $1(\% 1,4)$ 'i grade $V$ olarak değerlendirilmiştir. 
Tablo 5. Menenjiomalar için Simpson Sınıflandırma Sisitemi

\begin{tabular}{|llc|}
\hline Grade & Rezeksiyon & 10 - yllık rekurrens oranı \\
Grade I & Makroskopik GTR + dura, sinüs ve kemik rezeksiyonu & $\% 9$ \\
Grade II & Makroskopik GTR + dural bağlantının kuagulasyonu & $\% 19$ \\
Grade III & Sadece Makroskopik GTR & $\% 29$ \\
Grade IV & Subtotal parsiyel rezeksiyon & $\% 40$ \\
Grade V & Biyopsi & \\
\hline
\end{tabular}

Menenjiomaların hem cerrahi kararın verilmesinde hem de cerrahi sonrası yaşam kalitesi ve sürvi üzerinde etkili olan; hastaların yaşı, preoperatif performans skalası, tümörün lokalizasyonu, büyüklüğü, rezeksiyon derecesi, histopatolojik tanısı gibi birçok prognostik faktör rol oynamaktadır. Kavernöz sinüs, optik sinir kilıfl, petroklival bölge ve superior sagittal sinüs v.b. ulaşılması zor bölge tümörlerinde subtotal parsiyel rezeksiyon uygulanmaktadır. Bunun ise total rezeksiyona göre dört kat daha fazla mortalite riski bulunmaktadır $5,19,27,29,30$. Ayrica, bu bölgelerde total rezeksiyon yapılamazsa,yerine dekompresif cerrahi sonrası radyocerrahinin mortalitesi daha düşüktür7 ${ }^{7}$. Atipik menenjiomalarda da \%38-78 arasında 5 ylllı rekürrens oranı bulunmaktadır.

Cerrahi tedavi genç olan, semptomatik, kalsifikasyon bulunmayan, tümörde infiltrasyon ve genişleme bulunan hastalarda düşünülmelidir. Asemptomatik, yüksek ameliyat riski olan, yaşlı, kafa tabanı gibi ulaşılması zor lokalizasyonlarda tümörü bulunan hastalarda seri görüntülemelerle yakın takip tercih edilebilir. Bu takipte ilk MRG 3. ay olmak üzere, ikincisi 6 . ay ve sonrasında da yllık takipler önerilir. Hasta takiplerinde gerek görülürse, ve büyüme olursa cerrahi ve/veya radyocerrahi önerilir. Menenjiomaların komplikasyonlarl; histolopatolojik tipine ve yerleşim yerine göre değişmekle birlikte $\% 2-30$ oranında görülmektedir. Mortalite oranı ise \%1-14 arası değişmekte iken, yaşlı hastalarda bu oran daha yüksektirr,6,12,28. Bizim serimizde; postoperatif $3(\% 4,2)$ olguda medikal tedavi ile düzelen enfeksiyon gelişmiştir. $5 \quad(\% 6,9)$ hastanın nörolojik defisitinde artış olmuştur. Mortalite oranımız $3(\% 4,2)$ iken, morbidite oranımız 12 (\%16,6)'dir.

Radyoterapi (RT); rekürrensi olanlarda, subtotal eksizyon yapılmış olanlarda ve atipik veya malign menenjiomaların cerrahi tedavisi sonrasinda uygulanmaktadir ${ }^{11-13}$. Ortalama olarak 50-55 Gy median dozda yapılmaktadır. Stereotaksik olarak yapılan RT sıklıkla $<35 \mathrm{~mm}$ küçük olan tümörlere, cerrahiye uygun olmayan vakalarda, başka sistemik hastalığı olan yaşlı hastalarda uygulanmaktadır. Tümörde RT sonrası görülen volüm azalması, kitlenin lokal kontrolü açısından efektif ve güvenlidir10,32,33. Terapötik aralık \%50 izodozda 12-16 Gray'dir. Adjuvan olarak uygulanan RT nüks oranlarında düşüş sağlamaktadır ${ }^{10-12,15}$. Bizim çalışmamızda da atipik ve malign menenjiom tanısı almış 9 $(\% 12,5)$ hastamıza, cerrahi sonrasinda RT ve cyber veya gamma-knife uygulanmıştır.

Hormonoterapi, kemoterapi ve bioterapi son dekatlarda uygulanmakta olan diğer tedavi şekillerindendir. Kadınlarda fazla görülmesi ve progesteron reseptörünün \%70, östrojen reseptörünün ise $\% 30$ civarında pozitif olması gibi biyokimya bulguları, bu tümörlerin hormonal büyümeye sahip oldukları hipotezini desteklemektedir13,15,32,33. Hormonal tedavi rekürrens göstermiş olan tümörlerde ve ayrıca benign menenjiomalar için de uygulanmaktadır ${ }^{11,14,33}$. Tamoksifen ostrojen reseptörü antagonisti, mifepristone progesteron antagonisti olarak ve megestrol 
asetat ise oral progesteron agonisti olarak tedavide kullanılan ajanlardır ${ }^{11,13,33}$.

Rekombinant interferon alfa tedavisinin, invitro ekilmiş olan insan menenjiom hücrelerinde büyümeyi engellediği gösterilmiştir ${ }^{12,34}$. Yine in vitro olarak ekilmiş insan menenjiom hücrelerinde hydroxyurea'nin, apopitozu indükleyerek tümör büyümesini engelleyen oral kemoterapötik bir ajan olduğu gösterilmiştir ${ }^{3,15,35}$. Çoklu Kemoterapi (siklofosfamid, vinkristin, adriamisin,) ise; agresif, malign, cerrahi ve RT'ye direnç gösteren tümörlerde denenebilir ${ }^{34,36,37}$.

\section{SONUÇ}

İntrakranial menenjiomalar malign tipleri dışında; genellikle benign özellikte yavaş büyüyen, erken tanı konulup, total çıkarıldığında tam kür sağlanan, rekürrens oranı son derece düşük olan tümörlerdir. Menenjiomalarda cerrahi kararın verilmesinde ve survide; hastaların yaşı, preoperatif performans skalası, tümörün lokalizasyonu, büyüklügü, rezeksiyon derecesi, histopatolojik özellikleri gibi birçok faktör rol oynamaktadır. Asemptomatik, küçük boyutta, ameliyata uygun olmayan, yaşlı, kafa tabanı, kavernöz sinüs gibi ulaşılması zor lokalizasyonlarda bulunan hastalarda seri görüntülemelerle yakın takip ve gereğinde cerrahi/ radyocerrahi tercih edilebilir. Bu takiplerde de ilk MRG 3. ay olmak üzere, ikincisi 6. ay ve sonrasında da yıllık takipler önerilir. Genç olan ve kalsifikasyonu bulunmayanlarda hızlı büyüme riski nedeniyle cerrahi düşünülmelidir.

Çıkar Çatışması Beyanı: Yazarlar çıkar çatışması olmadığını bildirmişlerdir.

Finansal Destek: Bu çalışma her hangi bir fon tarafından desteklenmemiştir.

Declaration of Conflicting Interests: The authors declare that they have no conflict of interest.

Financial Disclosure: No financial support was received.

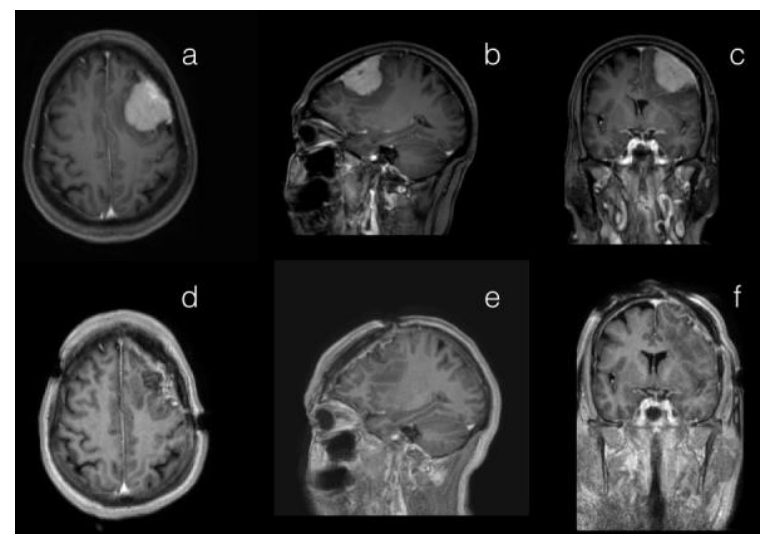

Resim 1. Sol fronto-pariatal konveksite menenjiomu olan 52 yaşındaki kadın hastamızın; preoperatif axial (a), sagittal (b) ve coronal (c) kesit kontrastlı kranial MRG görüntüleri (dural tail olması dikkati çekmektedir). Aynı hastamızın postoperatif axial (d), sagittal (f) ve coronal (g) kesit kontrastlı kontrol kranial MRG görüntüleri.

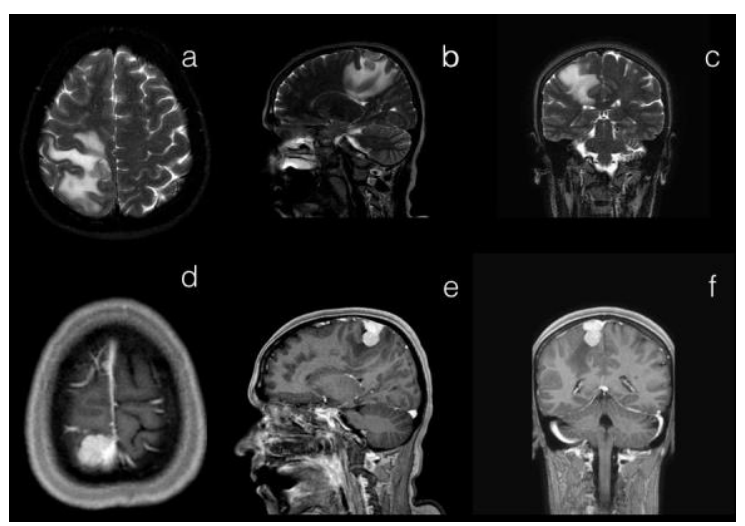

Resim 2. Sekretuvar menenjioma tanısı almış olan 43 yaşındaki kadın hastamızın; tümörü küçük olmasına rağmen peritümöral ödemin fazlalığını gösteren preoperatif axial (a), sagittal (b) ve coronal (c) kesit kontrastsız T2-ağırlıklı kranial MRG görüntüleri. Aynı hastamızın preoperatif axial (d), sagittal (f) ve coronal (g) kesit kontrastlı kranial MRG görüntüleri. 


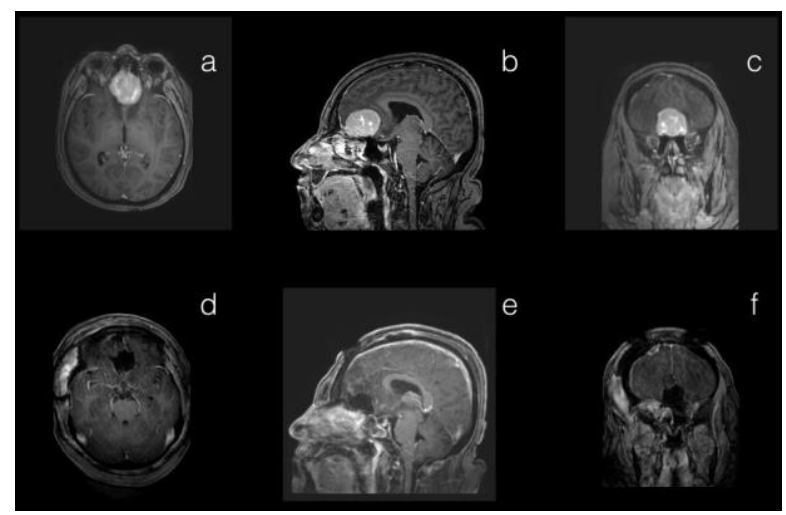

Resim 3. Olfaktor oluk menenjiomu olan 48 yaşındaki kadın hastamızın; preoperatif axial (a), sagittal (b) ve coronal (c) kesit kontrastlı kranial MRG görüntüleri. Aynı hastamızın postoperatif axial (d), sagittal (f) ve coronal (g) kesit kontrastll kontrol kranial MRG görüntüleri.

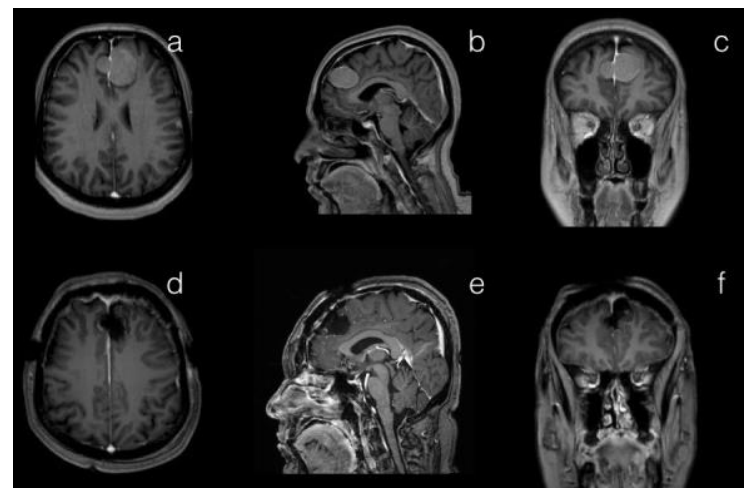

Resim 4. Falks menenjiomu olan 41 yaşındaki kadın hastamızın; preoperatif axial (a), sagittal (b) ve coronal (c) kesit kontrastlı kranial MRG görüntüleri. Aynı hastamızın postoperatif axial (d), sagittal (f) ve coronal (g) kesit kontrastlı kontrol kranial MRG görüntüleri.

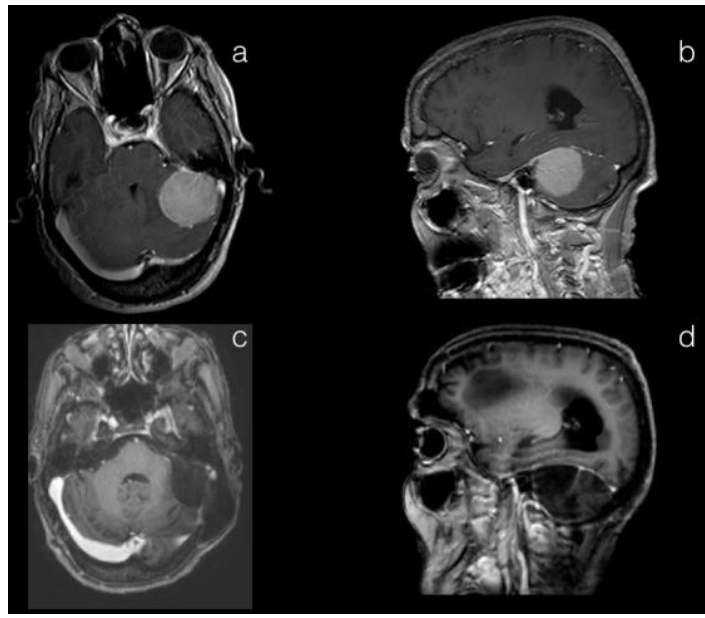

Resim 5. Tentorial yerleșimli menenjiomu olan 72 yașındaki kadın hastamızın; preoperatif axial (a), sagittal (b) kesit kontrastlı kranial MRG görüntüleri. Aynı hastamızın postoperatif axial (c), sagittal (d) kesit kontrastlı kontrol kranial MRG görüntüleri.

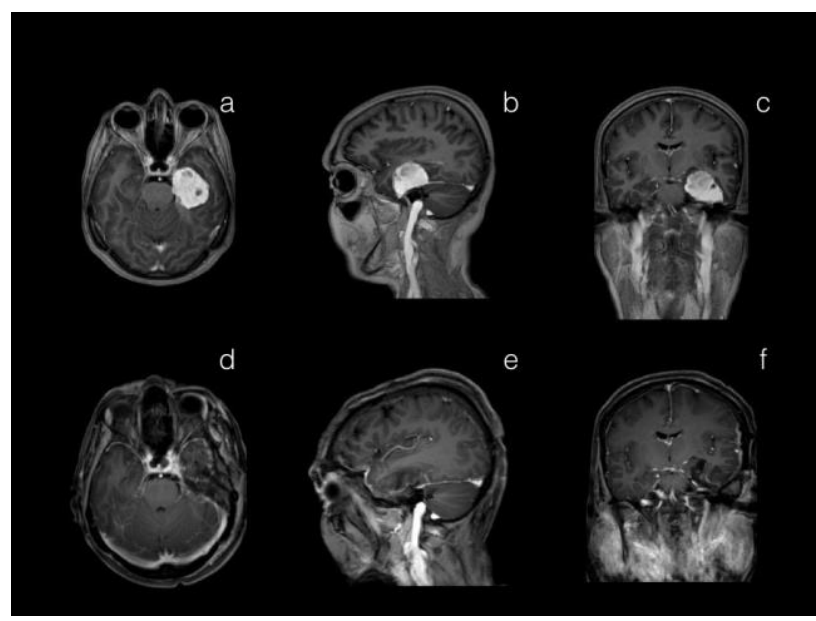

Resim 6. Orta fossada menenjiomu olan 50 yaşındaki kadın hastamızın; preoperatif axial (a), sagittal (b) ve coronal (c) kesit kontrastlı kranial MRG görüntüleri. Aynı hastamızın postoperatif axial (d), sagittal (f) ve coronal (g) kesit kontrastl kontrol kranial MRG görüntüleri.

\section{KAYNAKLAR}

1. Bondy M, Ligon BL. Epidemiology and etiology of intracranial meningiomas: a review. J Neurooncol. 1996; 29: 197-205.

2. Longstreth WT, Jr., Dennis LK, McGuire VM, Drangsholt MT, Koepsell TD. Epidemiology of intracranial meningioma. Cancer. 1993; 72: 639-48.

3. Nakasu S, Fukami T, Jito J, Nozaki K. Recurrence and regrowth of benign meningiomas. Brain Tumor Pathol. 2009; 26: 69-72.

4. Wiemels J, Wrensch M, Claus EB. Epidemiology and etiology of meningioma. J Neurooncol. 2010; 99: 30714.

5. Colakoglu N, Demirtas E, Oktar N, Yuntem N, Islekel S, Ozdamar N. Secretory meningiomas. J Neurooncol. 2003; 62: 233-41.

6. Niiro M, Yatsushiro K, Nakamura K, Kawahara Y, Kuratsu J. Natural history of elderly patients with asymptomatic meningiomas. J Neurol Neurosurg Psychiatry. 2000; 68: 25-8.

7. Apra C, Peyre M, Kalamarides M. Current treatment options for meningioma. Expert Rev Neurother. 2018; 18: 241-9.

8. Alexiou GA, Gogou P, Markoula S, Kyritsis AP. Management of meningiomas. Clin Neurol Neurosurg. 2010; 112: 177-82.

9. Firsching RP, Fischer A, Peters R, Thun F, Klug N. Growth rate of incidental meningiomas. J Neurosurg. 1990; 73: 545-7.

10. Black PM. Hormones, radiosurgery and virtual reality: new aspects of meningioma management. Can J Neurol Sci. 1997; 24: 302-6. 
11. Claus EB, Black PM, Bondy ML et al. Exogenous hormone use and meningioma risk: what do we tell our patients? Cancer. 2007; 110: 471-6.

12. Kaba SE, DeMonte F, Bruner JM et al. The treatment of recurrent unresectable and malignant meningiomas with interferon alpha-2B. Neurosurgery. 1997; 40: 2715.

13. Chamberlain MC, Glantz MJ, Fadul CE. Recurrent meningioma: salvage therapy with long-acting somatostatin analogue. Neurology. 2007; 69: 969-73.

14. Jhawar BS, Fuchs CS, Colditz GA, Stampfer MJ. Sex steroid hormone exposures and risk for meningioma. J Neurosurg. 2003; 99: 848-53.

15. Newton HB, Slivka MA, Stevens C. Hydroxyurea chemotherapy for unresectable or residual meningioma. J Neurooncol. 2000; 49: 165-70.

16. Phillips LE, Koepsell TD, van Belle G, Kukull WA, Gehrels JA, Longstreth WT, Jr. History of head trauma and risk of intracranial meningioma: population-based case-control study. Neurology. 2002; 58: 1849-52.

17. Sanson M, Cornu P. Biology of meningiomas. Acta Neurochir (Wien). 2000; 142: 493-505.

18. Rao S, Sadiya N, Doraiswami S, Prathiba D. Characterization of morphologically benign biologically aggressive meningiomas. Neurol India. 2009; 57: 744-8.

19. Bollag RJ, Vender JR, Sharma S. Anaplastic meningioma: progression from atypical and chordoid morphotype with morphologic spectral variation at recurrence. Neuropathology. 2010; 30: 279-87.

20. Bozkurt M, Göcmez C, Okçu M et al. Paraplegia due to missed thoracic meningioma after lumbar spinal decompression surgery: A case report and review of the literature. Dicle Medical Journal. 2014; 41: 210-3.

21. Jaaskelainen J. Seemingly complete removal of histologically benign intracranial meningioma: late recurrence rate and factors predicting recurrence in 657 patients. A multivariate analysis. Surg Neurol. 1986; 26: 461-9.

22. Braunstein JB, Vick NA. Meningiomas: the decision not to operate. Neurology. 1997; 48: 1459-62.

23. Buhl R, Nabavi A, Wolff S et al. MR spectroscopy in patients with intracranial meningiomas. Neurol Res. 2007; 29: 43-6.

24. Saloner D, Uzelac A, Hetts S, Martin A, Dillon W. Modern meningioma imaging techniques. J Neurooncol. 2010; 99: 333-40.
25. Pereira-Filho Nde A, Soares FP, Chemale Ide $M$, Coutinho LM. Peritumoral brain edema in intracranial meningiomas. Arq Neuropsiquiatr. 2010; 68: 346-9.

26. Louis DN, Perry A, Reifenberger G et al. The 2016 World Health Organization Classification of Tumors of the Central Nervous System: a summary. Acta Neuropathol. 2016; 131: 803-20.

27. Ichinose $\mathrm{T}$, Goto $\mathrm{T}$, Ishibashi $\mathrm{K}$, Takami $\mathrm{T}$, Ohata $\mathrm{K}$. The role of radical microsurgical resection in multimodal treatment for skull base meningioma. J Neurosurg. 2010; 113: 1072-8.

28. Landeiro JA, Goncalves MB, Guimaraes RD et al. Tuberculum sellae meningiomas: surgical considerations. Arq Neuropsiquiatr. 2010; 68: 424-9.

29. Shukla D, Behari S, Jaiswal AK, Banerji D, Tyagi I, Jain VK. Tentorial meningiomas: operative nuances and perioperative management dilemmas. Acta Neurochir (Wien). 2009; 151: 1037-51.

30. Paiva-Neto MA, Tella OI, Jr. Supra-orbital keyhole removal of anterior fossa and parasellar meningiomas. Arq Neuropsiquiatr. 2010; 68: 418-23.

31. Hastürk AE, Basmacı M, Canbay S et al. Intracranial Meningiomas: Analysis of 56 Patients. Türk Nöroşirürji Dergisi 2011, Cilt: 21, Sayl: 1, 1-7 1. 2011; 21: 1-7.

32. Lee JY, Niranjan A, McInerney J, Kondziolka D, Flickinger JC, Lunsford LD. Stereotactic radiosurgery providing long-term tumor control of cavernous sinus meningiomas. J Neurosurg. 2002; 97: 65-72.

33. Ojemann SG, Sneed PK, Larson DA et al. Radiosurgery for malignant meningioma: results in 22 patients. J Neurosurg. 2000; 93 Suppl 3: 62-7.

34. Kyritsis AP. Chemotherapy for meningiomas. J Neurooncol. 1996; 29: 269-72.

35. Gupta V, Su YS, Samuelson CG et al. Irinotecan: a potential new chemotherapeutic agent for atypical or malignant meningiomas. J Neurosurg. 2007; 106: 45562.

36. Chamberlain MC, Tsao-Wei DD, Groshen S. Temozolomide for treatment-resistant recurrent meningioma. Neurology. 2004; 62: 1210-2.

37. Chamberlain MC, Tsao-Wei DD, Groshen S. Salvage chemotherapy with CPT-11 for recurrent meningioma. J Neurooncol. 2006; 78: 271-6. 